\title{
Chlorine Dioxide: A Potential Mouth Rinse for Oral Health
}

\author{
Shubangi Mani, Ameet Mani, Rajiv Saini
}

\begin{abstract}
The current global and regional patterns of oral disease largely reflect distinct risk profiles across countries, related to living conditions, lifestyles and the implementation of preventive oral health systems. Periodontitis has been proposed as having an etiological or modulating role in cardiovascular diseases, diabetes, respiratory disease, adverse pregnancy outcome and other systemic diseases. Chlorine dioxide when stabilized in water and used at low concentration effectively neutralizes volatile sulfur compounds in the oral cavity. This compound has the ability to effectively clean oral tissues on a daily basis without causing harmful side effects.
\end{abstract}

Keywords: Chlorine, Periodontitis, Halitosis.

How to cite this article: Mani S, Mani A, Saini R. Chlorine Dioxide: A Potential Mouth Rinse for Oral Health. Int J Experiment Dent Sci 2012;1(2):118-119.

\section{Source of support $\mathrm{Nil}$}

\section{Conflict of interest None}

Dental caries and periodontal disease have historically been considered the most important global oral health burdens. The current global and regional patterns of oral disease largely reflect distinct risk profiles across countries, related to living conditions, lifestyles and the implementation of preventive oral health systems. Periodontitis is a destructive inflammatory disease of the supporting tissues of the teeth and is caused either by specific microorganisms or by a group of specific microorganisms, resulting in progressive destruction of periodontal ligament and alveolar bone with periodontal pocket formation, gingival recession or both. ${ }^{1}$ One of these mechanisms is based on the potential effects of the inflammatory phenomenon of periodontitis on the systemic dissemination of the locally produced mediators, such as C-reactive protein (CRP), interleukin- 1 beta (IL-1 $\beta$ ) and interleukin-6 (IL-6) and tumor necrosis factor alpha $(\mathrm{TNF}-\alpha)^{2}{ }^{2}$ Periodontitis has been proposed as having an etiological or modulating role in cardiovascular diseases, diabetes, respiratory disease and adverse pregnancy outcome. $^{3}$ Scientific studies have proven the relationship between periodontal disease and oral cancer, breast cancer, infertility and kidney disease. Observational nonexperimental studies have shown that subjects who have periodontal infections, such as gingivitis and periodontitis have higher levels of CRP than subjects without gingivitis and periodontitis respectively, supporting the hypothesis that these oral infections increase CRP levels. ${ }^{4}$ Chlorine dioxide $\left(\mathrm{ClO}_{2}\right)$ is a little known ingredient in oral hygiene yet it is safe and effective for everyday use. $\mathrm{ClO}_{2}$ is a colorless and odorless gas that can be stabilized in an aqueous solution. It has been used to purify drinking water in water treatment plants around the world. It has also been used as a powerful disinfectant and bleaching agent in other applications. $\mathrm{ClO}_{2}$ when stabilized in water and used at low concentration effectively neutralizes volatile sulfur compounds in the oral cavity. This compound has the ability to effectively clean oral tissues on a daily basis without causing harmful side effects. When properly formulated $\mathrm{ClO}_{2}$ is odorless and tasteless to the end user it will not cause burning, drying or staining with continued use as compared to traditional alcohol and chlorhexidine-based mouth rinses. When formulated at low levels, $\mathrm{ClO}_{2}$ is not a harsh bactericidal compound. It will effectively breakdown volatile sulfur compounds that cause bad breath and lead to periodontal disease. U sing oral care products with $\mathrm{ClO}_{2}$ on a daily basis will promote oral health and total body health safely. $\mathrm{ClO}_{2}$ is used widely in various fields for its safe and high antibacterial action. Sodium chlorite $\left(\mathrm{NaClO}_{2}\right)$, equivalent to $\mathrm{ClO}_{2}$, the traditional ingredient in almost all oxygen supplementation today, is a nontoxic substance approved by the US Food and D rug A dministration (FDA) as an antimicrobial agent. More scientific studies and clinical trials will further prove the beneficial effect of $\mathrm{ClO}_{2}$ and its vital role in oral health. Oxyfresh Worldwide Inc. manufactures a wide range of quality dental products that uses $0 x y g e n{ }^{\circledR}$ - pure and stabilized form of chlorine dioxide. It safely neutralizes the sulfur bonds in cellular by-products, which are responsible for malodors. The company also manufacture the products with combination of sodium chlorite and zinc formulas to reduce the harmful effects of volatile sulfur compound (VSCs).

\section{REFERENCES}

1. Saini R, Saini S, Sharma S. Periodontal disease linked to cardiovascular disease. J Cardiovasc Dis Res 2010;1:161-62.

2. Saini R, Saini S, Saini SR. Periodontal diseases: A risk factor to cardiovascular diseases. A nn Card A naesth 2010;13:159-61.

3. Saini R, Saini S, Sharma S. Periodontitis lead to VAP in ICU patients: A dental note. J Pharm Bioallied Sci 2010;2:377.

4. Mani A, V advadgi V, A narthe R, Saini R, M ani S. A clinical study on dental air force home dental cleaning system on adult 
chronic periodontitis patients and its assessment to $\mathrm{C}$-reactive protein levels. Int J Experiment Dent Sci 2012;1(1):14-18.

\section{ABOUT THE AUTHORS}

\section{Shubangi Mani (Corresponding Author)}

A ssociate Professor, Department of Orthodontics, Rural Dental College Loni, M aharashtra, India, e-mail: drshubangimani2608@gmail.com

\section{Ameet Mani}

A ssociate Professor, Department of Periodontology, Rural Dental College, Loni, M aharashtra, India

\section{Rajiv Saini}

A ssistant Professor, Department of Periodontology, Rural Dental College, A hmednagar, M aharashtra, India 